\title{
Prevalence of HIV type 1 drug resistance mutations in treatment-naïve and experienced patients from resource-limited settings with universal access to antiretroviral therapy: a survey in two small Brazilian cities
}

\author{
Walter A Eyer-Silva/1,2,3/+, José Carlos Couto-Fernandez, Carlos Silva-de-Jesus, Mariza G Morgado \\ Laboratório de Aids \& Imunologia Molecular, Instituto Oswaldo Cruz-Fiocruz, Av. Brasil 4365, 21045-900, Rio de Janeiro, RJ, Brasil \\ ${ }^{1}$ Hospital Universitário Gaffrée e Guinle, Universidade Federal do Estado do Rio de Janeiro, RJ, Brasil ²Programa Municipal de HIV-1/Aids

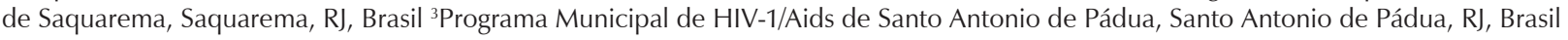

Concerns have been raised that universal availability of antiretroviral agents in resource-limited settings might lead to the emergence and spread of resistant strains. We present the largest survey on human immunodeficiency virus type 1 (HIV-1) resistance among treatment-nä̈ve and experienced patients followed in small, relatively underprivileged cities in Brazil with universal availability to standard of care antiretroviral combinations. Samples were collected between 2004 and 2006 from 95 patients followed in the cities of Saquarema and Santo Antonio de Pádua, state of Rio de Janeiro. A proviral fragment encompassing protease and reverse transcriptase (RT) regions was generated and drug susceptibility level was inferred. Among 50 strains from drug-naïve subjects, one (2\%) had intermediate-level resistance to RT inhibitors. Among 38 patients on therapy as of sampling, 28 (73.7\%) had plasma viral load (PVL) below detection limit (26 of whom without evidence of resistance mutations) and 11 (28.9\%) harbored strains with reduced susceptibility. Only two strains harbored both protease and RT inhibitor mutations. Among seven patients who were off-treatment as of sampling, two (28.5\%) harbored strains with reduced susceptibility to $R T$ inhibitors. The relatively high frequency of undetectable PVL among patients on treatment and the overall low prevalence of resistance-associated mutations are reassuring. Continued surveillance, however, is necessary.

Key words: antiretroviral therapy - Brazil - human immunodeficiency virus type 1 - resistance

In Brazil standard of care highly active antiretroviral therapy (HAART) regimens are freely available to human immunodeficiency virus type 1 (HIV-1)-infected subjects through the national health care system since 1996, as part of a remarkable response against the epidemic (Marins et al. 2003, Teixeira et al. 2004). Universal access to antiretroviral drugs requires an uninterrupted effort to ensure adequate adherence and continued surveillance on the prevalence of resistant strains in the community. Concerns have been raised that widespread availability of antiretroviral drugs in resource-poor settings might lead to the emergence and spread of resistant variants due to suboptimal compliance. Up to the present time, this seems not to be the case in Brazil (Soares et al. 2004). When compared to figures reported from developed nations, most studies from Brazil have found relatively low rates of primary HIV-1 drug resistance (Brindeiro et al. 1999, Dumans et al. 2002, Brindeiro et al. 2003, Pires et al. 2004, Brigido et al. 2005, Eyer-Silva \& Morgado 2005, Barreto et al. 2006, Medeiros et al. 2006, Rodrigues et al. 2006, SaFerreira et al. 2007), even though isolated surveys recently reported worrisome rates in the port cities of Santos (Sucupira et al. 2007) and Salvador (Pedroso et al. 2007). Also, resistance rates in Brazil are being reported

+ Corresponding author: walter-eyer@unirio.br

Received 10 August 2007

Accepted 20 March 2008 from studies primarily based in large urban centers and little is known about the prevalence of resistant strains in innermost parts of the country. Since the AIDS epidemic is a growing problem in relatively small Brazilian cities (Szwarcwald et al. 2000, Eyer-Silva et al. 2005, Eyer-Silva \& Morgado 2006, Eyer-Silva et al. 2007a), where standard of care HAART combinations are also universally available, it will be essential to study the prevalence of resistance-associated mutations in such settings. To the best of our knowledge, a previous report from our group is the sole study addressing this issue that has been published to date in peer reviewed journals (Eyer-Silva \& Morgado 2005).

To further expand our knowledge in this field, we present herein the results of a cross-sectional survey on the prevalence of mutations associated with antiretroviral drug resistance among patients receiving care in two small cities of inner state of Rio de Janeiro, Southeast Brazil: Saquarema and Santo Antonio de Pádua. Since these cities have been assigned relatively low human development index values (http://www.ipea.gov.br/), the present study is an opportunity to assess the prevalence of resistant strains and the efficacy of antiretroviral therapy in relatively underprivileged settings in Brazil with widespread access to standard of care HAART regimens.

\section{PATIENTS, MATERIALS AND METHODS}

Saquarema is situated $116 \mathrm{Km}$ north from the city of Rio de Janeiro, in the so called Sun Coast region. Bathed by the Atlantic, Saquarema attracts thousands of domestic and foreign visitors during summer months. Santo 
Antonio de Pádua is situated in Northwestern state of Rio de Janeiro, $263 \mathrm{Km}$ far from the capital, at the border of the state of Minas Gerais. As of the year 2000, these two cities counted 61,591 and 42,078 inhabitants and had been assigned human development index values of 0.762 and 0.754 , respectively, which corresponds to positions 45th and 50th among the 92 cities of the state of Rio de Janeiro (http://www.ipea.gov.br/). The municipal HIV/ AIDS programs of Saquarema and Santo Antonio de Pádua were established in the years 2000 and 2001, respectively. Before the establishment of these programs, HIV-1-infected patients had to be referred for treatment elsewhere. Blood samples are regularly collected for plasma viral load (PVL) measurements and CD4 cell counts. Most patients from these cohorts attributed the acquisition of HIV-1 infection to unprotected heterosexual intercourse. The similar HDI values of these cities do not necessarily mean that they share comparable epidemiologic characteristics. In fact, previous clinical, epidemiological and phylogenetic investigations have found that each city has its own epidemiologic and virologic pattern of epidemic spread (Eyer-Silva \& Morgado 2007, Eyer-Silva et al. 2007a, b).

After signed informed consent, blood samples were collected, DNA was extracted from peripheral blood mononuclear cells (PBMC), and the sequence of a single fragment of HIV-1 polymerase gene encompassing the whole protease (PR) and reverse transcriptase (RT) amino acids 1-230 was generated using a previously described in-house protocol Eyer-Silva and Morgado (2005). All sequences generated were subjected to quality control measures to ensure there were no sample mix-ups or contamination (Learn et al. 1996). Drug susceptibility level was inferred by submitting the FASTA files of generated strains to the on-line drug resistance interpretation system available at the Stanford HIV resistance database website (http://hivdb.stanford.edu). The Stanford HIV database algorithm then assigns a drug resistance score for each mutation, which is translated into five levels of inferred antiretroviral resistance: susceptible, potential low-level, low-level, intermediate and high-level resistance. In the present report, secondary PR inhibitor mutations known to occur as natural polymorphisms are not reported, even if it is known that they may also contribute to resistance when present with other mutations. Subtyping and recombination analyses were performed by applying maximum likelihood phylogenetic recon- structions and the bootscanning method, as previously described (Eyer-Silva \& Morgado 2006). The study protocol was reviewed and approved by the Ethics Review Board at Instituto de Pesquisa Clínica Evandro Chagas, Fundação Oswaldo Cruz, Rio de Janeiro. The nucleotide sequences of HIV-1 polymerase sequences reported in this study were deposited in the GenBank database under accession numbers DQ899698 through DQ899727 and EF042627 through EF042690.

\section{RESULTS}

Between the years of 2004 and 2006 a total of 120 HIV-1 infected patients received care in the municipal HIV-1/AIDS programs of the two cities. Sequences generated from samples of $95(79 \%)$ of these patients (91 adult and 4 pediatric cases) were available for phylogenetic and genotypic analyses. Seventy-seven sequences $(81 \%)$ were assigned subtype B. The remaining strains were assigned subtypes F1 ( 8 strains; 8.4\%), CRF02_AG (2 strains; $2.1 \%$ ), D (1 strain; $1 \%$ ), and unique BF1 recombinants (7 strains; $7.4 \%$ ).

Table I presents the prevalence of mutations known to confer reduced drug susceptibility in the 95 studied subjects. Fifty samples were from treatment-naïve subjects and 45 from antiretroviral-experienced patients. Among the latter, 38 were on HAART regimens as of sampling and seven were off-treatment due to diverse reasons such as non-compliance, transient treatment interruption due to adverse events, and previous vertical transmission prophylaxis which was withhold after delivery.

Among 50 strains recovered from drug naïve patients, we found RT inhibitor-associated mutations in seven (14\%), including one strain (2\%) with intermediatelevel resistance (06BRSQ-94), five strains with potential low-level resistance and one sequence (05BRSQ-83_P) which harbored the V118I mutation and was considered susceptible to NRTI (Table II).

Table III presents the clinical, epidemiological, and virological data of the 45 treatment-experienced patients. Among seven patients with prior antiretroviral exposure but who were off treatment as of sampling, two (28.5\%) harbored strains with reduced drug susceptibility. These mutations were K103N (strain 05BRSQ-21) and M184V (05BRSQ-33). Both these patients were off treatment due to non-compliance.

Among 38 patients on therapy (between 3 months and 10 years) as of sampling, 28 (73.7\%) had PVL below de-

\section{TABLE I}

Prevalence of mutations known to confer reduced susceptibility to antiretroviral agents among 50 treatment-naïve and 45 antiretroviral-experienced HIV-1-infected patients receiving care in two small cities of the state of Rio de Janeiro, Brazil, 2004-2006

\begin{tabular}{|c|c|c|c|c|c|}
\hline & \multirow[t]{2}{*}{$\mathrm{n}$} & \multicolumn{3}{|c|}{ Presence of mutations known to confer reduced susceptibility } & \multirow[t]{2}{*}{ Total } \\
\hline & & RT only & PR only & $\mathrm{RT}+\mathrm{PR}$ & \\
\hline \multicolumn{6}{|l|}{ Treatment-experienced patients $(n=45)$} \\
\hline Patients on HAART as of sampling & 38 & $8(21 \%)$ & $1(2.6 \%)$ & $2(5.2 \%)$ & $11(28.9 \%)$ \\
\hline Patients off-treatment as of sampling & 7 & $2(28.5 \%)$ & - & - & $2(28.5 \%)$ \\
\hline Treatment-naïve subjects & 50 & $7(14 \%)$ & - & - & $7(14 \%)$ \\
\hline Total & 95 & $17(17.9 \%)$ & $1(1 \%)$ & $2(2.1 \%)$ & $19(20 \%)$ \\
\hline
\end{tabular}




\section{TABLE II}

Clinical, epidemiological, and virological data of seven treatment-naïve patients whose samples yielded polymerase sequences harboring mutations known to confer reduced antiretroviral susceptibility

\begin{tabular}{lccccc}
\hline Patient $^{a}$ & sex/age/CDC & subtype & RT/PR & RT mutations & PR mutations \\
\hline 05BRSAP26 & F/32/A2 & $\mathrm{B}$ & $\mathrm{S} / \mathrm{S}$ & $\mathrm{V} 179 \mathrm{D}$ & - \\
05BRSAP28 & $\mathrm{F} / 38 / \mathrm{C} 3$ & $\mathrm{~B}$ & $\mathrm{~S} / \mathrm{S}$ & $\mathrm{V} 179 \mathrm{D}$ & - \\
06BRSAP30 & $\mathrm{M} / 32 / \mathrm{A} 1$ & $\mathrm{~B}$ & $\mathrm{~S} / \mathrm{S}$ & $\mathrm{T} 9 \mathrm{~N}$ & - \\
06BRSAP31 & $\mathrm{F} / 23 / \mathrm{A} 2$ & $\mathrm{~B}$ & $\mathrm{~S} / \mathrm{S} 179 \mathrm{D}$ & - \\
06BRSAP33 & $\mathrm{M} / 23 / \mathrm{A} 3$ & $\mathrm{~B}$ & $\mathrm{~S} / \mathrm{S}$ & $\mathrm{V} 179 \mathrm{D}$ & - \\
05BRSQ-83_P & $\mathrm{M} / 06 / \mathrm{A} 2$ & $\mathrm{~B}$ & $\mathrm{~S} / \mathrm{S}$ & $\mathrm{V} 118 \mathrm{I}$ & - \\
06BRSQ-94 & $\mathrm{F} / 46 / \mathrm{C} 3$ & $\mathrm{~B}$ & $\mathrm{R} / \mathrm{S}$ & $\mathrm{D} 67 \mathrm{~N}, \mathrm{~K} 70 \mathrm{~S}, \mathrm{~T} 215 \mathrm{D}$ & -
\end{tabular}

$a$ : the first two digits indicate the year of sample collection; the suffix _ $\mathrm{P}$ indicates a pediatric patient; $b$ : prediction of drug susceptibility to RT and PR inhibitors: S (susceptible or potential low-level resistance); R (low-level, intermediate or high-level resistance to any drug).

tection limit (26 of whom without evidence of resistance mutations). Eleven (28.9\%) strains had resistance-associated mutations and reduced drug susceptibility and 27 (71\%) had no mutations. Eight strains (21\%) had mutations in the RT gene only, two (5.2\%) in both RT and PR, and one $(2.6 \%)$ in PR only. Recorded mutations in the RT gene were: the nucleoside analog mutations M41L (5 strains), L210W (1), and T215Y (5), which lead to removal of nucleoside RT inhibitors (NRTI) already incorporated in the growing DNA chain; mutation M184V (5), which causes resistance due to sterical inhibition to NRTI; and mutations associated with non-nucleoside RT inhibitors (NNRTI) resistance, such as K103N (3), Y181C (1), Y188L (1), and G190A (2). Multinucleoside resistance mutations of the Q151M complex and insertions at codon 69 were not found. Recorded primary mutations to PR inhibitors were L24I (1), D30N (1), L33F (2), I54V (1), V82A (1), and N88D (1). Genotypic patterns clearly suggestive of non-adherence or drug pharmacokinetic failure were found in at least three patients on treatment: strains 04BRSQ-39 and 05BRSQ-70 were recovered from patients on virologic failure, yet no resistance mutations were detected; the patient carrying sequence 05BRSQ-15 was on virologic failure besides no mutation to his current regimen was detected (Table III). In contrast, three patients had PVL levels below detection limits besides the presence of mutations RT-M184V (04BRSAP01), RT-T215Y (04BRSAP07), and PR-L33F (04BRSQ-06). These three patients were on highly active, lopinavir-including regimens.

\section{DISCUSSION}

The present study is the largest analysis of the prevalence of antiretroviral resistance among treatment-naïve and experienced patients followed in small Brazilian cities with universal availability of standard of care HAART regimens. Since we wished to study all patients (regardless of treatment history), including those with PVL below detection limit, we chose to perform resistance testing by targeting HIV-1 DNA from the PBMC proviral compartment, instead of the most commonly used plasma HIV-1 RNA. Although studies have found that the detection of resistance mutations in the HIV-1 RNA plasma compartment may precede that in PBMC
(Kaye et al. 1995, Bi et al. 2003), it has been shown that HIV DNA recovered from the proviral compartment can reliably be used in drug resistance genotyping (Devereux et al. 2000, Sarmati et al. 2003, Chew et al. 2005, Parisi et al. 2007, Vicenti et al. 2007). In addition, proviral sequences can be useful to detect archived mutations that can compromise future therapeutic options, such as those selected by previously used regimens (Sarmati et al. 2003, SG Parisi et al. unpublished observations), and have been found to have greater sensitivity after treatment interruption in treatment experienced patients (Venturi et al. 2002). In fact, in this study we demonstrate the occurrence of previously selected resistance mutations in three patients with PVL bellow detection limit (04BRSAP01, 04BRSAP07, 04BRSQ-06) and two patients who were off-treatment as of sampling (05BRSQ-21, 05BRSQ-33). Proviral sequences also allow genotyping analysis in patients with low to undetectable PVL and may be useful in such patients when a change in the antiretroviral combination is being considered due to toxicity or when a simplified regimen is necessary.

A total of four group M subtypes (B, D, F1, CRF02 $A G)$ and several unique BF1 recombinants were uncovered in this survey. The demonstration of such a molecular diversity in these two small, inner cities further highlights the complexity of the HIV-1 epidemic in Brazil. An overall low prevalence of mutations conferring antiretroviral resistance was found in both treatmentnaïve and experienced patients. The prediction of drug susceptibility found that one out of $50(2 \%)$ strains recovered from drug-naïve subjects had intermediate-level resistance to thymidine analog RT inhibitors (with lowlevel resistance to abacavir, didanosine, and tenofovir). This strain (sequence 06BRSQ-94) harbored one established drug-resistance mutation (D67N) associated with two additional mutations at established drug-resistance positions: K70S and T215D. Mutation K70S has already been recorded under a stavudine plus didanosine combination, in a patient with previous exposure to zidovudine and lamivudine (Lawrence et al. 1999). Mutation T215D has been described in drug-naïve subjects as a non-wild type revertant of mutations T215Y or T215F (Miller et al. 2000). In the Stanford HIV resistance database (http:// cpr.stanford.edu/cpr/), T215D mutation is present in 


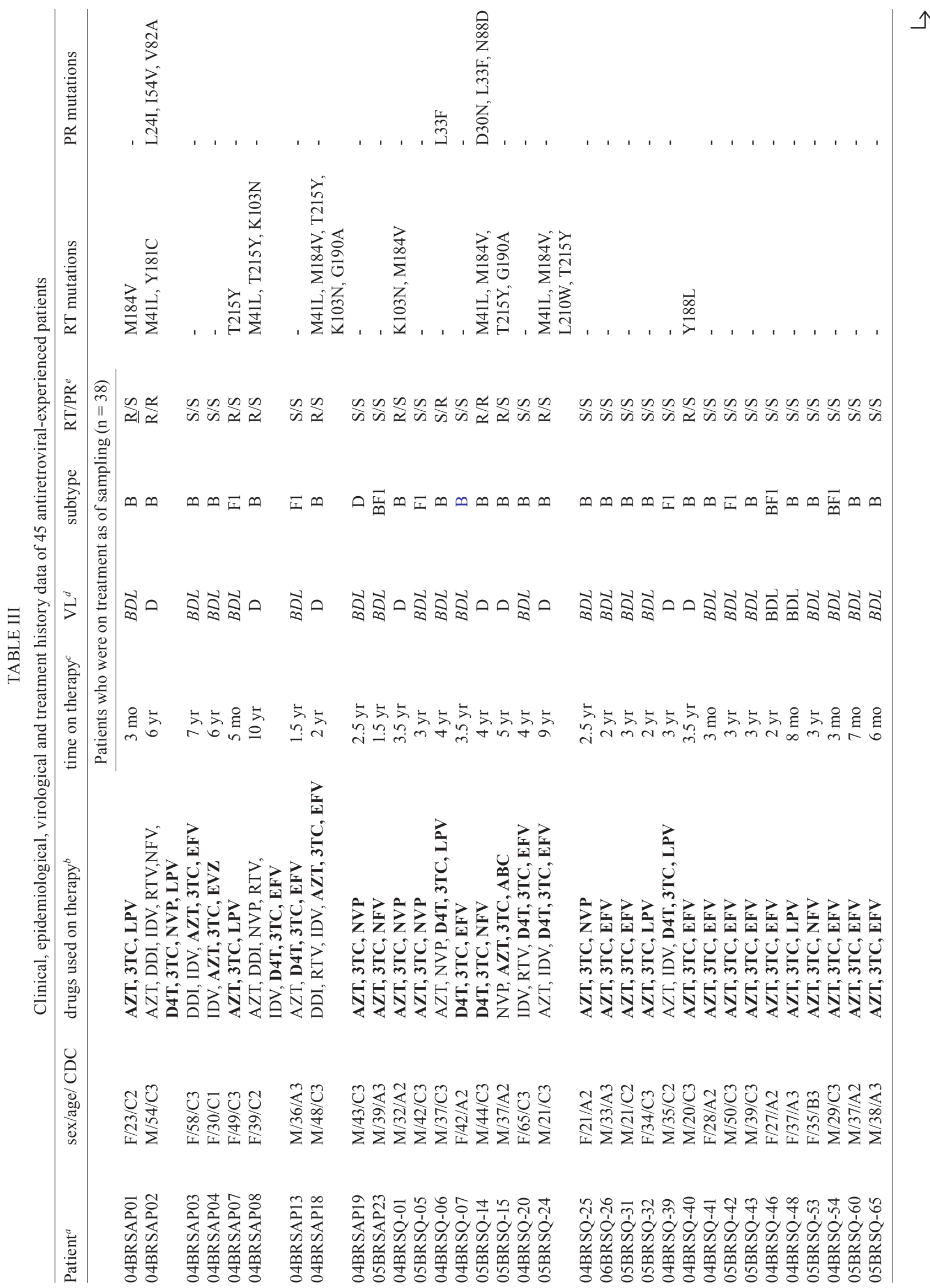




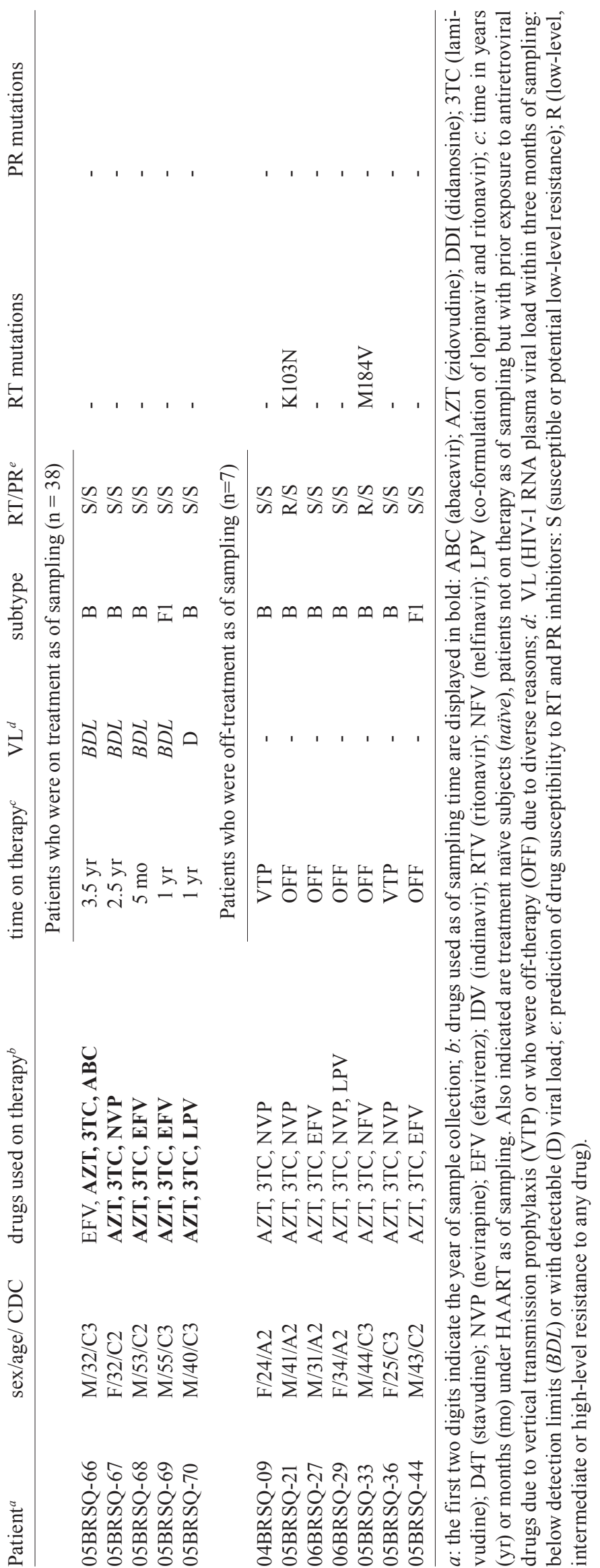


$0.2 \%$ and $0.7 \%$ of sequences recovered from drug-naïve and drug-treated patients, respectively. T215D mutation seems to emerge due to fitness advantage and is fully susceptible to NRTI, yet their presence leads to faster reappearance of resistant 215 viruses under the pressure of thymidine analogues (Garcia-Lerma et al. 2001, Violin et al. 2004). This implies that a strain with intermediate resistance to thymidine analogs has been transmitted or that prior antiretroviral therapy was deliberately omitted.

Six additional strains from drug-naïve subjects harbored mutations known to be associated with resistance to RT inhibitors. Sequence 05BRSQ-83_P presented mutation V118I, which occurs in around $2 \%$ of untreated subjects and has been described in treatment-naive Brazilian patients (Dumans et al. 2002, Brindeiro et al. 2003). This strain was predicted as susceptible to RT inhibitors. Four strains (05BRSAP26, 05BRSAP28, 06BRSAP31, and 06BRSAP33) harbored the polymorphism V179D, which occurs in $3.1 \%$ of subtype B-infected drug-naïve subjects and causes potential low-level resistance to each available NNRTI (Rhee et al. 2005). Phylogenetic analyses (data not shown) demonstrated that these four strains form a strong monophylectic cluster and were recovered from patients who probably took part in the same chain of viral spread. Whether this intriguing cluster from the city of Santo Antonio de Pádua represents a reservoir of a variant with natural resistance to NNRTI and with potential to spread is unknown. Strain 06BRSAP30 presented the T69N mutation, which poses potential lowlevel resistance to several NRTI (Winters \& Merigan 2001). This mutation is by far the most common nonaspartic acid change at codon 69 (Winters \& Merigan 2001) and has also been reported from drug-naïve Brazilian patients (Pires et al. 2004).

Among 38 patients who were on antiretroviral combinations as of sampling, 28 (73.7\%) had PVL below detection limits (26 of whom without evidence of resistance mutations). Only two strains harbored resistance mutations to both RT and PR inhibitors. Although three strains presented a genotypic pattern suggestive of nonadherence (or drug pharmacokinetic failure), the overall figures stand for a high rate of success of antiretroviral therapy in these real-life underprivileged settings.

The present study has a number of limitations. Traditional population-based sequencing may not consistently detect minor drug-resistant variants and thus may be insensitive to strains resistant to previously used drugs and to detect decayed resistant variants transmitted to untreated subjects. A comprehensive panel of strains could only be detected by extensive clonal sequencing from a polymerase chain reaction product. As already discussed, targeting the plasma viral compartment may reveal resistant variants not yet abundant within circulating PBMC. The overall number of studied subjects is limited, as well as the geographic span of the survey.

The relatively high frequency of plasma viral load below detection limits among patients on treatment and the overall low prevalence of mutations associated with reduced drug susceptibility presented herein are reassuring and in accordance with a previous, smaller survey carried out by our group in another small city in state of Rio de Janeiro (Eyer-Silva \& Morgado 2005). Nevertheless, the continued widespread access to antiretroviral combinations in Brazil, including in relatively small cities from the innermost parts of the country, needs to be accompanied by an uninterrupted effort to ensure adherence and regular, comprehensive surveys on the prevalence of resistant strains in the community.

\section{ACKNOWLEDGEMENTS}

To the patients for agreeing to participate in this study. To the many dedicated health care professionals in Saquarema and Santo Antonio de Pádua, without whom this study could not be possible.

\section{REFERENCES}

Barreto CC, Nishyia A, Araujo LV, Ferreira JE, Busch MP, Sabino EC 2006. Trends in antiretroviral drug resistance and clade distributions among HIV-1-infected blood donors in São Paulo, Brazil. $J$ Acquir Immune Defic Syndr 41: 338-341.

Bi X, Gatanaga H, Ida S, Tsuchiya K, Matsuoka-Aizawa S, Kimura S, Oka S 2003. Emergence of protease inhibitor resistance-associated mutations in plasma HIV-1 precedes that in proviruses of peripheral blood mononuclear cells by more than a year. J Acquir Immune Defic Syndr 34: 1-6.

Brigido LF, Franco HM, Custodio RM, Oliveira CA, P Ferreira JL, Eira M, Bergel F, Araujo F, Carvalheiro JR, Rodrigues R 2005. Molecular characteristics of HIV type 1 circulating in Sao Paulo, Brazil. AIDS Res Hum Retroviruses 21: 673-682.

Brindeiro R, Vanderborght B, Caride E, Correa L, Oravec RM, Berro O, Stuyver L, Tanuri A 1999. Sequence diversity of the reverse transcriptase of human immunodeficiency virus type 1 from untreated Brazilian individuals. Antimicrob Agents Chemother 43: 1674-1680.

Brindeiro RM, Diaz RS, Sabino EC, Morgado MG, Pires IL, Brigido L, Dantas MC, Barreira D, Teixeira PR, Tanuri A 2003. Brazilian Network for HIV Drug Resistance Surveillance (HIV-BResNet): a survey of chronically infected individuals. AIDS 17: 1063-1069.

Chew CB, Potter SJ, Wang B, Wang YM, Shaw CO, Dwyer DE, Saksena NK 2005. Assessment of drug resistance mutations in plasma and peripheral blood mononuclear cells at different plasma viral loads in patients receiving HAART. J Clin Virol 33: 206-216.

Devereux HL, Loveday C, Youle M, Sabin CA, Burke A, Johnson M 2000. Substantial correlation between HIV type 1 drug-associated resistance mutations in plasma and peripheral blood mononuclear cells in treatment-experienced patients. AIDS Res Hum Retroviruses 16: 1025-1030.

Dumans AT, Soares MA, Pieniazek D, Kalish ML, De Vroey V, Hertogs K, Tanuri A 2002. Prevalence of protease and reverse transcriptase drug resistance mutations over time in drug-naive human immunodeficiency virus type 1-positive individuals in Rio de Janeiro, Brazil. Antimicrob Agents Chemother 46: 3075-3079.

Eyer-Silva WA, Basilio-de-Oliveira CA, Morgado MG 2005. HIV infection and AIDS in a small municipality in Southeast Brazil. Rev Saude Publica 39: 950-955.

Eyer-Silva WA, Couto-Fernandez JC, Morgado MG 2007a. Molecular epidemiology of HIV type 1 in inner Rio de Janeiro State, Brazil. AIDS Res Hum Retroviruses 23: 303-308.

Eyer-Silva WA, Freire MAL, Gayão ML, Basilio-de-Oliveira CA, Morgado MG 2007b. Epidemiologic features of HIV infection in 3 small cities in inner Rio de Janeiro State, Brazil. Rev Inst Med Trop São Paulo 49: 303-307. 
Eyer-Silva WA, Morgado MG 2005. A genotyping study of human immunodeficiency virus type-1 drug resistance in a small Brazilian municipality. Mem Inst Oswaldo Cruz 100: 869-873.

Eyer-Silva WA, Morgado MG 2006. Molecular epidemiology of HIV-1 infection in a small Brazilian county: usefulness of envelope and polymerase sequences to epidemiologic studies. J Acquir Immune Defic Syndr 41: 664-670.

Eyer-Silva WA, Morgado MG 2007b. Autochthonous horizontal transmission of a CRF02_AG strain revealed by a human immunodeficiency virus type 1 diversity survey in a small city in inner Rio de Janeiro, Southeast Brazil. Mem Inst Oswaldo Cruz 102: 809-815.

Garcia-Lerma JG, Nidtha S, Blumoff K, Weinstock H, Heneine W 2001. Increased ability for selection of zidovudine resistance in a distinct class of wild-type HIV-1 from drug-naive persons. Proc Natl Acad Sci U S A 98: 13907-13912.

Kaye S, Comber E, Tenant-Flowers M, Loveday C 1995. The appearance of drug resistance-associated point mutations in HIV type 1 plasma RNA precedes their appearance in proviral DNA. AIDS Res Hum Retroviruses 11: 1221-1225.

Lawrence J, Schapiro J, Winters M, Montoya J, Zolopa A, Pesano R, Efron B, Winslow D, Merigan TC 1999. Clinical resistance patterns and responses to two sequential protease inhibitor regimens in saquinavir and reverse transcriptase inhibitor-experienced persons. J Infect Dis 179: 1356-1364.

Learn GH Jr, Korber BT, Foley B, Hahn BH, Wolinsky SM, Mullins JI 1996. Maintaining the integrity of human immunodeficiency virus sequence databases. J Virol 70: 5720-5730.

Marins JR, Jamal LF, Chen SY, Barros MB, Hudes ES, Barbosa AA, Chequer P, Teixeira PR, Hearst N 2003. Dramatic improvement in survival among adult Brazilian AIDS patients. AIDS 17: 1675-1682.

Medeiros LB, Lacerda HR, Cavalcanti AMS, Albuquerque MFPM 2006. Primary resistance of human immunodeficiency virus type 1 in a reference center in Recife, Pernambuco, Brazil. Mem Inst Oswaldo Cruz 101: 845-849.

Miller V, Ait-Khaled M, Stone C, Griffin P, Mesogiti D, Cutrell A, Harrigan R, Staszewski S, Katlama C, Pearce G, Tisdale M 2000. HIV-1 reverse transcriptase (RT) genotype and susceptibility to RT inhibitors during abacavir monotherapy and combination therapy. AIDS 14: 163-171.

Parisi SG, Boldrin C, Cruciani M, Nicolini G, Cerbaro I, Manfrin V, Dal Bello F, Franchin E, Franzetti M, Rossi MC, Cattelan AM, Romano L, Zazzi M, Andreoni M, Giorgio P 2007. Both HIV Cellular DNA and Plasma RNA Sequencing are Useful for Detection of Drug Resistance Mutations in Antiretroviral Naive Patients. J Clin Microbiol45: 1783-1788.

Pedroso C, Queiroz AT, Alcantara LC, Drexler JF, Diaz RS, Weyll N, Brites C 2007. High Prevalence of Primary Antiretroviral Resistance Among HIV-1-Infected Adults and Children in Bahia, a Northeast State of Brazil. J Acquir Immune Defic Syndr 45: 251-253.

Pires IL, Soares MA, Speranza FA, Ishii SK, Vieira MC, Gouvea MI, Guimaraes MA, de Oliveira FE, Magnanini MM, Brindeiro RM,
Tanuri A 2004. Prevalence of human immunodeficiency virus drug resistance mutations and subtypes in drug-naive, infected individuals in the army health service of Rio de Janeiro, Brazil. $J$ Clin Microbiol 42: 426-430.

Rhee SY, Fessel WJ, Zolopa AR, Hurley L, Liu T, Taylor J, Nguyen DP, Slome S, Klein D, Horberg M, Flamm J, Follansbee S, Schapiro JM, Shafer RW 2005. HIV-1 Protease and reverse-transcriptase mutations: correlations with antiretroviral therapy in subtype $\mathrm{B}$ isolates and implications for drug-resistance surveillance. J Infect Dis 192: 456-465.

Rodrigues R, Scherer LC, Oliveira CM, Franco HM, Sperhacke RD, Ferreira JL, Castro SM, Stella IM, Brigido LF 2006. Low prevalence of primary antiretroviral resistance mutations and predominance of HIV-1 clade $\mathrm{C}$ at polymerase gene in newly diagnosed individuals from south Brazil. Virus Res 116: 201-207.

Sa-Ferreira JA, Brindeiro PA, Chequer-Fernandez S, Tanuri A, Morgado MG 2007. Human immunodeficiency virus-1 subtypes and antiretroviral drug resistance profiles among drug-naive Brazilian blood donors. Transfusion 47: 97-102.

Sarmati L, Nicastri E, Uccella I, D’Ettorre G, Parisi SG, Palmisano L, Galluzzo C, Concia E, Vullo V, Vella S, Andreoni M 2003. Drug-associated resistance mutations in plasma and peripheral blood mononuclear cells of human immunodeficiency virus type 1-infected patients for whom highly active antiretroviral therapy is failing. J Clin Microbiol 41: 1760-1762.

Soares MA, Brindeiro RM, Tanuri A 2004. Primary HIV-1 drug resistance in Brazil. AIDS 18 (Suppl. 3): S9-13.

Sucupira MC, Caseiro MM, Alves K, Tescarollo G, Janini LM, Sabino EC, Castelo A, Page-Shafer K, Diaz RS 2007. High levels of primary antiretroviral resistance genotypic mutations and B/F recombinants in Santos, Brazil. AIDS Patient Care STDS 21: 116-128.

Szwarcwald CL, Bastos FI, Esteves MA, de Andrade CL 2000. The spread of the AIDS epidemic in Brazil from 1987 to 1996: a spatial analysis. Cad Saude Publica 16: 7-19.

Teixeira PR, Vitoria MA, Barcarolo J 2004. Antiretroviral treatment in resource-poor settings: the Brazilian experience. AIDS 18 (Suppl. 3): S5-7.

Venturi G, Romano L, Carli T, Corsi P, Pippi L, Valensin PE, Zazzi M 2002. Divergent distribution of HIV-1 drug-resistant variants on and off antiretroviral therapy. Antivir Ther 7: 245-250.

Vicenti I, Razzolini F, Saladini F, Romano L, Zazzi M 2007. Use of peripheral blood DNA for genotype antiretroviral resistance testing in drug-naive HIV-infected subjects. Clin Infect Dis 44: $1657-1661$.

Violin M, Cozzi-Lepri A, Velleca R, Vincenti A, D’Elia S, Chiodo F, Ghinelli F, Bertoli A, d'Arminio Monforte A, Perno CF, Moroni M, Balotta C 2004. Risk of failure in patients with 215 HIV-1 revertants starting their first thymidine analog-containing highly active antiretroviral therapy. AIDS 18: 227-235.

Winters MA, Merigan TC 2001. Variants other than aspartic acid at codon 69 of the human immunodeficiency virus type 1 reverse transcriptase gene affect susceptibility to nuleoside analogs. Antimicrob Agents Chemother 45: 2276-2279. 